\title{
Lipid Droplet-Associated Proteins in Cardiomyopathy
}

\author{
Weiwei Huang ${ }^{a, b}$ Fei Gao ${ }^{b} \quad$ Yuting Zhang $^{b} \quad$ Tianhui Chen ${ }^{c, d}$ Chen Xub

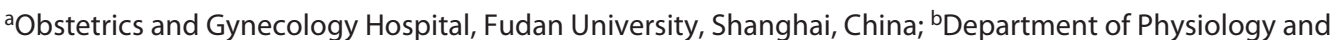 \\ Pathophysiology, State Key Laboratory of Medical Neurobiology, School of Basic Medical Sciences, Fudan \\ University, Shanghai, China; 'Department of Ophthalmology and Vision Science, Eye and ENT Hospital of Fudan \\ University, Shanghai, China; ${ }^{d}$ Key Laboratory of Myopia of State Health Ministry, and Key Laboratory of Visual \\ Impairment and Restoration of Shanghai, Shanghai, China
}

\section{Keywords}

Lipid droplets · Lipid droplet-associated proteins .

Cardiomyopathy $\cdot$ Heart

\begin{abstract}
Background: The heart requires a high rate of fatty-acid oxidation (FAO) to meet its energy needs. Neutral lipids are the main source of energy for the heart and are stored in lipid droplets (LDs), which are cytosolic organelles that primarily serve to store neutral lipids and regulate cellular lipid metabolism. LD-associated proteins (LDAPs) are proteins either located on the surface of the LDs or reside in the cytosol and contribute to lipid metabolism. Therefore, abnormal cardiac lipid accumulation or FAO can alter the redox state of the heart, resulting in cardiomyopathy, a group of diseases that negatively affect the myocardial function, thereby leading to heart failure and even cardiac death. Summary: LDs, along with LDAPs, are pivotal for modulating heart lipid homeostasis. The proper cardiac development and the maintenance of its normal function depend largely on lipid homeostasis regulated by LDs and LDAPs. Overexpression or deletion of specific LDAPs can trigger myocardial dysfunction and may contribute to the development of cardiomyopathy. Extensive connections and interactions may also exist between
\end{abstract}

karger@karger.com

(c) 2021 S. Karger AG, Basel

www.karger.com/anm

Karger!
LDAPs. Key Message: In this review, the various mechanisms involved in LDAP-mediated regulation of lipid metabolism, the association between cardiac development and lipid metabolism, as well as the role of LDAPs in cardiomyopathy progression are discussed.

(c) 2021 S. Karger AG, Basel

\section{Introduction}

Lipids are biological macromolecules that dissolve in nonpolar solvents including triglycerides (TAGs), phospholipids, glycolipids, cholesterol, and cholesterol esters $[1,2]$. Although different lipids perform different roles in regulating cellular function, their main functions are related to energy storage and signal transduction and serve as one of the primary components of the cell membrane. Additionally, lipids also play a non-negligible role in the process of individual growth and development along with homeostasis regulation. Therefore, it is pivotal for the body to maintain lipid regulation at a normal stage and within a feasible range.

The heart is the "engine" of the human body. It generally functions as a pump, promoting blood circulation via myocardial contraction and relaxation to provide nutri- 
ents and oxygen to the brain and other tissues to satisfy metabolic needs, and to remove the final metabolites from the tissues and organs to perpetuate normal cellular functions. Therefore, the heart requires the highest amount of energy supply and also possesses the strongest fatty-acid oxidation (FAO) capacity among other organs and tissues to meet its energy need. A large amount of energy used to maintain sustained cardiac contraction is provided primarily by mitochondrial $\beta$-oxidation fatty acids (FAs) [3]. Since healthy adult cardiomyocytes use FAs as their main energy substrate, lipid regulation is vital in cardiac metabolism [4].

\section{Lipid Metabolism in the Heart}

The heart requires large amounts of FAs for its energy supply. However, the heart does not actively use glucose or amino acids as a substrate for the de novo synthesis of FAs like the liver [5]. Therefore, the heart needs to continuously obtain FAs from the circulation [3, 6-8]. Plasma FAs can be ingested into the heart by 2 major pathways: (1) the lipolysis of plasma lipoprotein TAGs by lipoprotein lipases which are synthesized, processed, and abundantly expressed primarily in cardiomyocytes, or (2) the ingestion of albumin-bound serum-free FAs (FFAs) that are released from adipose tissue [9-11]. The heart can also obtain FAs by internalizing whole lipoproteins or by catabolizing the cardiac storage of endogenous TAGs [9]. FAs are esterified and converted to TAGs via acyl-CoA synthetase and FA transport protein, which are then stored in the form of lipid droplets (LDs) and are used for the subsequent hydrolysis to provide FAs for oxidation and can also serve as peroxisome proliferator-activated receptor a (PPARa) ligands [12-14]. The heart has relatively low TAG stock, which indicates its high lipolytic turnover rate compared to other tissues [15].

\section{Lipid Droplets}

LDs are crucial for regulating lipid metabolism. They are intracellular organelles that are expressed ubiquitously in all eukaryotic cells. Structurally, LDs consist of a phospholipid monolayer surrounding its lipid core [16, 17]. Lipidomics shows that the core of LDs can store $>160$ different types of neutral lipids, primarily TAGs, sterol esters, retinol esters, and waxes [16, 18-20]. The specific content of neutral lipids in the LDs of different cells varies with cell functions $[21,22]$.

Recent studies have provided substantial evidence on $\mathrm{LD}$ formation. The mainstream perspective is that the $\mathrm{LDs}$ are originated from the perilipin (PLIN) 2-rich domain of the endoplasmic reticulum (ER) [23]. This model of LD biogenesis is comprised of at least 4 major steps, including (1) synthesis of TAGs on the ER by diglyceride acyltransferase (DGAT), mainly DGAT2 [24, 25]; (2) formation of oil mirrors on the ER membrane; (3) generation of nascent LDs through budding; and (4) interaction of LDs with specific proteins for growth and expansion. Moreover, the plasma membrane is also participating by providing TAGs for LDs, and the Golgi apparatus has a close interaction with LDs [26-29]. In addition to neutral lipid and phospholipid synthesis enzymes, proteins such as seipins, PLINs, FIT proteins, and ER-shaping proteins also serve critical roles in LD formation. However, the exact mechanism of LD formation still needs further investigation.

The size of an LD is increased mainly via 3 different ways: fusion, caveolae conversion, and local synthesis [26, $30-35]$. The fusion model states that fat-specific protein 27 is capable of interacting with PLIN1 to form a channellike junction between 2 LDs and in this way, promote the trafficking of neutral lipids from one LD to the other [34]. The caveolae model suggests that exogenously administered oleic acid can be taken up by primary adipocytes and converted into TAGs directly in PLIN1-localized plasma membrane caveolae. It was also observed that human lysophosphatidylcholine acyltransferases 1 and 2 were localized to LDs with their expression levels correlated with the ability of LDs to synthesize phosphatidylcholine locally. This provides evidence for the local synthesis model [32]. LDs can be broken down by 2 pathways: (1) lipolysis by lipases such as adipose TAG lipase (ATGL) and hormone-sensitive lipase (HSL) and (2) delivery to autolysosomes to be broken down by lysosomal acid lipases through the autophagic process $[32,36]$. In the starvation state, TAG hydrolysis is upregulated to supply adequate FFA for $\beta$-oxidation to fulfill cellular energy requirements. Concurrently, the breakdown of LDs by lipophagy serves as an additional energy source. The suppression of lysosomal activity was associated with increased cellular TAG and cholesterol content as well as LD accumulation [37]. LDs were seen to co-localize with lysosomal-associated membrane protein type 1 in oleate or methionine- and choline-deficient medium (MCDM), and increased under lysosomal inhibition. Further research also showed that autophagy-related LD breakdown was probably relevant to LD-associated proteins (LDAPs) such as ATGL, the PLIN family, and the Rab family [38-44]. After LD degradation, the FAs stored in LDs are released, followed by $\beta$-oxidation in mitochondria and peroxisomes for its conversion to energy [45]. 


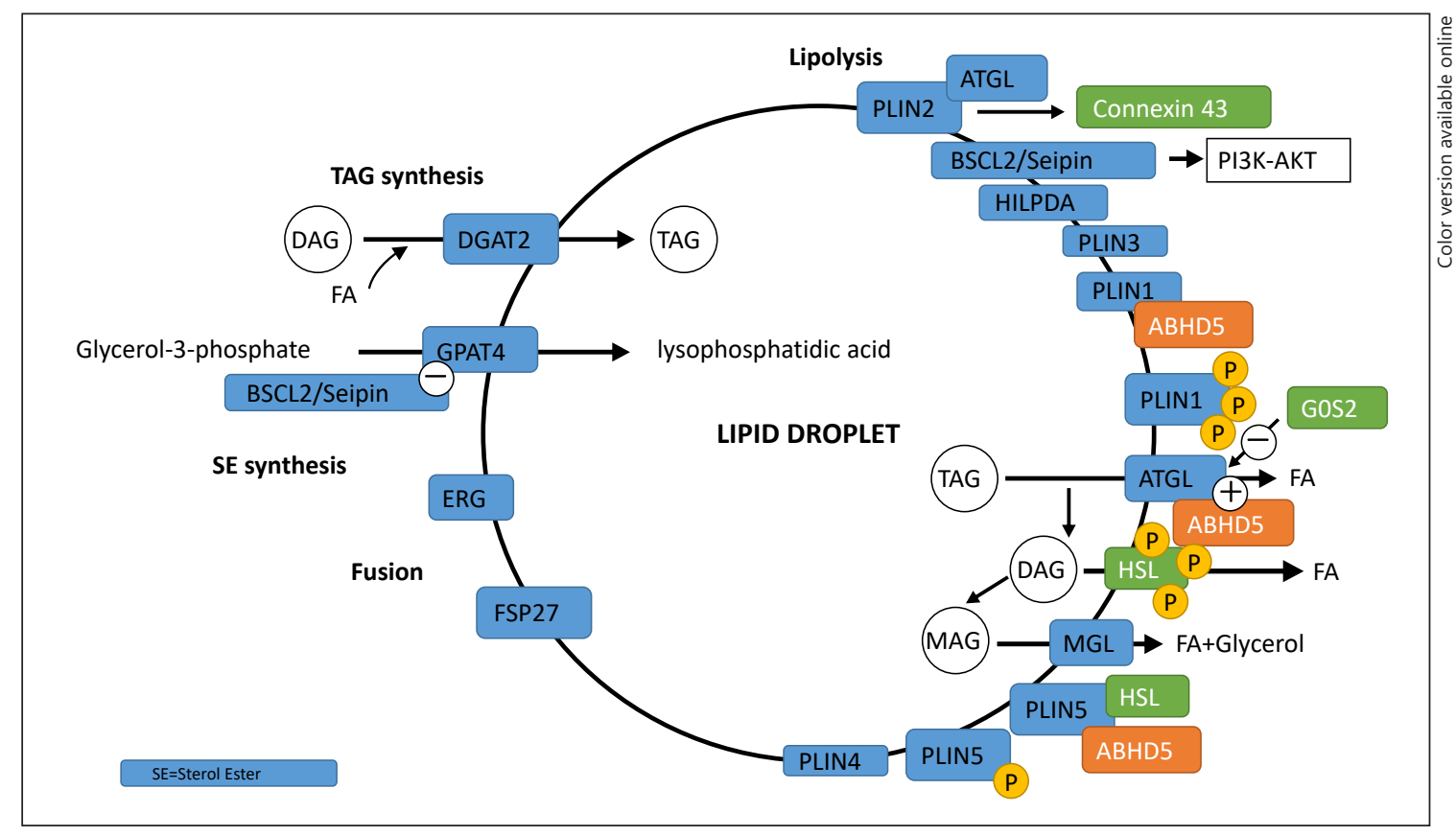

Fig. 1. Schematic diagram of LDAPs on the surface of the LD. Different LDAPs have different lipid-regulating abilities. LDAP, lipid droplet-associated proteins; LD, lipid droplet; PLIN, perilipin; ATGL, adipose triglyceride lipase; BSCL2, Berardinelli-Seip congenital lipodystrophy type 2; HILPDA, hypoxia-inducible lipid droplet-associated protein; HSL, hormone-sensitive lipase; FA, fatty acid; TAG, triglyceride; DAG, diacylglycerols; FSP27, fat-specific protein 27; DGAT, diglyceride acyltransferase.

LDs were initially considered fat deposits, which were specifically used to store neutral lipids for energy use. Recent studies have shown that LDs are more than just fat reservoirs. LD functions in numerous biological processes, including the storage of various substances such as vitamins [46, 47], signaling precursors [48-50], proteins [51-53], membrane synthesis [16], cell signaling [32, 54, 55], protein handling, and management of cellular stress [16]. LDs can also protect cells from lipotoxicity by sequestering toxic lipids, for example, ceramides and diacylglycerols (DAGs), in the cytoplasm [16].

\section{LD-Associated Proteins}

LDAPs are proteins which predominantly regulate the extremely high LD turnover rate of the heart [56]. LDAPs are also fundamental to the formation and degradation of LDs. These proteins can be localized to the surface of the LD through 2 major pathways: the class I pathway and the class II pathway. In the class I pathway, proteins are inserted into a particular ER membrane domain, potentially a hairpin loop. They are subsequently repositioned from the ER to the LD surface as membrane-embedded proteins using membrane bridges. In the class II pathway, proteins are bound to the LD surface via an amphiphilic helix or through multiple amphiphilic and hydrophobic helices [57, 58].

Studies have discovered numerous variations of LDAPs. LDAPs, including the PLIN family, the cell deathinducing DNA fragmentation factor-like (CIDE) family, abhydrolase domain containing 5 (ABHD5/CGI-58), ATGL, Berardinelli-Seip congenital lipodystrophy type 2 (BSCL2), and hypoxia-inducible LDAP (HILPDA) have been extensively studied. Within the human body, the PLIN family comprises of 5 members, including PLIN1, PLIN2 (PLIN2/adipophilin/adipose differentiation-related protein/ADFP), PLIN3 (PLIN3/Tip47), PLIN4 (PLIN4/S3-12), and PLIN5 (PLIN5/lipid storage droplet protein 5/myocardial LD protein/OXPAT/PAT1). The CIDE family includes 3 members: CIDEA, CIDEB, and CIDEC (termed fat-specific protein 27 in mice) [59-63]. Although all cells collect LDs to a variable extent, the expression of LDAPs in LDs of different cells depends on the function of cell types and tissues. Since the composition of LDAPs in each cell type and tissue should fulfill its functional demands, different LDAPs have different lipid-regulating abilities (summarized in Fig. 1). 
The first recognized LDAP was PLIN1, which was primarily located in the white adipose tissue (WAT) and brown adipose tissue (BAT) [64]. PLIN2 and PLIN3 are commonly expressed in all cell types. Specifically, PLIN2 is strongly activated by lipid overload and is massively expressed in macrophages, atherosclerotic plagues, the liver, and muscles. PLIN3 is mainly located on the surface of LDs but can be found in the cytoplasm when not associated with LDs. PLIN4 is predominantly found in WAT but is also detectable in tissues, such as the heart and the muscles. PLIN5, on the other hand, is chiefly expressed within oxidative tissues, such as the heart, BAT, the liver, and skeletal muscles. Both ABHD5 and PLIN5 can be phosphorylated by protein kinase A (PKA), leading to the activation of ATGL. ATGL is another well-known LDAP, which is found in all cell types that contain neutral lipids. ATGL is generally found on the surface of LDs. BSCL2 is a protein found in the ER that can interact with nascent LDs directly and facilitate the maturation of LDs from the ER [65]. Also, high levels of HILPDA have been identified in the WAT, BAT, heart, and lungs of mice [66].

Generally, the PLIN family is known to be involved in modulating lipase activity. Under primary conditions, PLINs tend to limit the hydrolysis of LDs and, subsequently, the release of FAs. PLIN1 interacts with comparative gene identification (CGI)-58 (CGI-58) to interrupt the passage of hydrolases into LDs, thus protecting the TAGs in LDs from hydrolysis $[67,68]$. Also, PLIN5 attenuates the myocardial ischemia/reperfusion injury by suppressing LD lipolysis to lessen oxidative stress [69]. However, upon stimulation, PLIN1 and PLIN5 have been observed to promote hydrolysis to provide tissues with FAs for oxidation and energy [12]. Additionally, LDs combined with PLIN2 are protected from breakdown by the proteasome pathway $[70,71]$. LDAPs are also engaged in the process of intracellular cargo transportation. PLIN3 binds to the cytoplasmic domain of mannose 6-phosphate receptor, facilitating the translocation of mannose 6-phosphate receptor from endosomes to the trans-Golgi network [72]. Meanwhile, PLIN5 was observed to bind to LD-derived monounsaturated FAs and transport them to the nucleus, following the activation of cAMP/PKA-mediated lipolysis [73].

\section{Cardiac Dysfunction Associated with Lipid Metabolic Disorders}

Lipids act as the substrates of mitochondrial $\beta$-oxidation; play vital roles in signal transduction, membrane structure, and molecular transport; and are essen- tial regulators of cardiac function [74-77]. Lipid homeostasis is a crucial part of the normal development of the heart. During the early stages of heart development, glycolysis is the primary energy source for the heart. As cardiomyocytes maturate and terminate their differentiation, the oxidative capacity of mitochondria enhances, and FAO progresses to become the major source of energy for the heart. If the adult heart is subjected to excessive stress that cannot be fully compensated by cardiac hypertrophy, the energy metabolism of the heart would convert to a fetal-like type. Glycolysis is enhanced, whereas mitochondrial FAO diminishes. Hence, alterations in cardiac energy metabolism throughout the development of the heart have critical implications for the maturation ability of cardiomyocytes [78]. Abnormal accumulation of cardiac lipids is typically associated with 2 forms of cardiomyopathy: obesity-related cardiomyopathy, which might lead to sudden death, and diabetic cardiomyopathy, which usually has a failing cardiac function $[79,80]$. In addition, visceral fat accumulation is also associated with excess epicardial and pericardial fat $[79,81,82]$. Therefore, lipid metabolic disorders are closely related to progressive cardiac dysfunction.

Certain lipids can be directly toxic to the heart. Earlier studies have considered TAGs to be potentially toxic. A study that directly compared the progression of cardiac dysfunction in ob/ob and $\mathrm{db} / \mathrm{db}$ mouse models identified that metabolic dysfunction and myocardial TAG accumulation preceded the onset of contractile dysfunction, and myocardial TAG accumulation preceded the occurrence of contractile dysfunction and hyperglycemia [83]. Clinical studies also found elevated intramyocardial TAGs in patients with heart failure and diabetes with or without obesity, whose gene expression profiles resemble the Zucker diabetic fat rodent model, an animal model of lipotoxicity. Consistently, the same pattern of altered mRNA expression was undetected in heart failure hearts without lipid accumulation [84]. Further findings also suggested that TAGs may not be directly cytotoxic but may serve as markers of lipotoxicity. FA metabolites that are indeed cardiolipotoxic include ceramides, DAGs, acyl-coenzyme synthase 1 (ACSL1), acylcarnitines, and lysophospholipids, where ceramides and DAGs are the major toxic lipids [85]. Mice with overexpressed long-chain ACSL1 accumulate FFA, DAG, and ceramide and exhibit mitochondrial and cardiac dysfunction. At the same time, the overexpression of DGAT1, a TAG-synthesizing enzyme which utilizes FFA to convert DAG to TAG, improves ACSL1-induced cardiac dysfunction by reducing cardiomyocyte apoptosis as well as attenuating DAG and 
ceramide levels. Thus, cardiac-specific DGAT1 transgenic mice show massive amounts of TAG accumulation but reduced cardiac ceramide, DAG, and FA levels without an overt cardiac phenotype [86]. In human studies, patients implanted with a left-ventricular assist device, which promotes the use of FAs by the myocardium, exhibit decreased ceramide and DAG levels but similar TAG and FA levels. This indicates that myocardial lipotoxicity might be caused by ceramide and DAG rather than TAG [87].

Several mechanisms have been proposed to explain how this occurs, including direct toxic effects of neutral droplets or FAs on myocardial myofiber function, FAinduced apoptosis, generation of reactive oxygen species (ROS) as toxic byproducts of lipid oxidation, and activation of signaling pathways via protein kinase C (PKC) activation or ceramide-mediated processes [88]. Although DAGs are thought to be more efficient lipid second messengers that activate classical and novel isoforms of PKC, both DAGs and ceramides bind to PKC, thereby mediating myocardial contractility, gene expression, and cell growth [75]. $\mathrm{PKCa}^{-1-}$ mice showed enhanced cardiac contractile ability and were less susceptible to heart failure [89]. The inhibition of PKC $\beta$ preserved the heart from diabetic cardiac diastolic dysfunction and cardiomyocyte hypertrophy [90], and mice with $\mathrm{PKC} \beta_{2}$ overexpression exhibited left-ventricular hypertrophy as well as cardiomyocyte necrosis [91]. Novel PKC isoforms such as PKC $\theta$ and $\mathrm{PKC} \varepsilon$ exert regulatory effects through the insulin signaling pathway [85]. Furthermore, the structure of DAGs can affect their PKC activation capabilities. It is suggested that cellular DAGs are characterized by 3 different stereoisomers.

The insulin-signaling defect might be another pathway used by DAGs and ceramides to produce lipotoxicity. Studies have suggested that both ceramide and DAGs can negatively regulate insulin action. Ceramide interrupts insulin-mediated activation of the Akt/PKB pathway either by the direct inhibition of Akt/PKB phosphorylation or indirectly by the activation of the protein phosphatase $2 \mathrm{~A}$ to dephosphorylate Akt/PKB, whereas DAG acts by promoting the phosphorylation of IRS-1, which can contribute to the development of cardiomyopathy [92].

Cardiac dysfunction could also occur due to enhanced FA oxidation and subsequent changes in the substrates of energy metabolism. Normally, the heart relies primarily on mitochondrial $\beta$-oxidation of FAs for energy. However, the heart also acts as a metabolic omnivore with the ability to metabolize glucose, amino acids, and ketone bodies. This metabolic diversity and flexibility have contributed to the maintenance of normal contractile function of the heart under various physiological and pathophysiological conditions. Thus, excess FAs in the obese heart may result in enhanced mitochondrial FA $\beta$-oxidation, reducing glucose utilization by causing substrate competition and triggering insulin resistance. There are at least 2 possible explanations for this shift in oxidative substrates to impair cardiac function: (1) FA intake exceeds the capacity of LDs to be stored safely and (2) the heart produces energy less efficiently with greater oxygen consumption as mitochondrial $\beta$-oxidation of FAs is more oxygen-intensive than glucose oxidation $[82,93,94]$. Leptin is a protein hormone synthesized and secreted by WAT and is known for its ability to inhibit food intake, reduce energy intake, and increase energy expenditure. Generally, leptin mRNA is ubiquitously expressed in all myocardium and has higher expression in the atria than the ventricles [95]. Felines with hypertrophic cardiomyopathy have been shown to exhibit elevated cardiac leptin transcription compared with those without heart diseases, indicating enhanced FA oxidation under pathological conditions [95] (summarized in Fig. 2).

\section{LDAPs and Cardiomyopathy}

As mentioned, the dysregulation of cardiac lipids affects the myocardial systolic and diastolic functions, leading to the occurrence of cardiomyopathies. Therefore, maintaining cardiac lipid homeostasis is especially important. LDs are organelles that serve as mediators of lipid metabolism. LDAPs are functional proteins of LDs [63, 96]. Dysfunction of cardiac LDAPs may affect cardiac function, resulting in cardiomyopathies.

Within the heart, the major LDAPs include PLIN2, PLIN3, PLIN4, and PLIN5 [75]. Recent studies have also detected the protein expression of ABHD5, ATGL, BSCL2, and HILPDA in the heart. Among these LDAPs, PLIN2, PLIN5, ABHD5, and ATGL are relatively wellcharacterized, while there is a scarcity of reports on HILPDA, and its function remains unclear. Although PLIN1 is undetected in the heart, PLIN1 deficiency has been shown to impact the function of the myocardium. Several studies have tried to illustrate the relationship between different LDAPs and cardiomyopathy (shown in Table 1). We will provide a detailed introduction to the role of 4 main LDAPs in cardiac lipid metabolism and cardiomyopathies. 


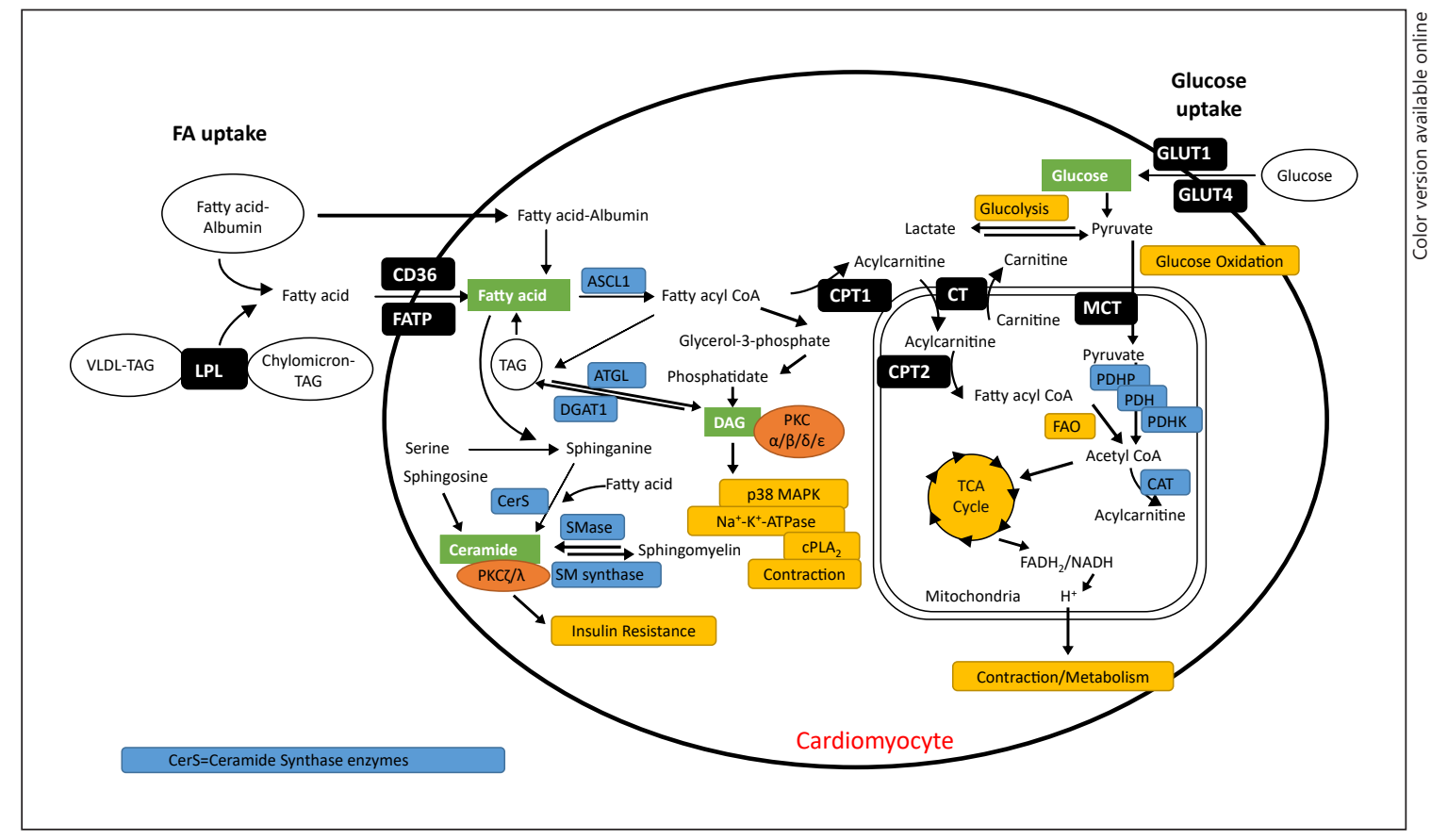

Fig. 2. Schematic diagram of energy metabolism in the heart. The metabolic diversity and flexibility have contributed to the maintenance of normal contractile function of the heart under various physiological and pathophysiological conditions. FA, fatty acid; TAG, triglyceride; DGAT, diglyceride acyltransferase; ATGL, adipose triglyceride lipase; FAO, fatty-acid oxidation; PKC, protein kinase C.

\section{Perilipin 2}

PLIN2 was identified in LDs of preadipocytes and was found to be replaced by PLIN1 after the differentiation and maturation of preadipocytes [97]. Previous studies demonstrated that both overexpression and deficiency of PLIN2 can contribute to LD accumulation. PLIN2 has also been proven to promote LD formation, FA-induced insulin secretion, as well as LD stabilization [97, 98].

Transgenic mice with heart-specific overexpression of PLIN2 showed an accumulation of small LDs around the mitochondria with massive TAG deposition in the atria. Still, notably, the heart weights of WT and Tg mice were comparable, with their hearts being analogous in terms of mitochondrial size as well as shape. They suffered from tolerance-induced myocardial infarction. The overexpression of HSL can overcome the tendency of steatosis of PLIN2 [98]. PLIN2-induced LDs were sensitive to lipolytic stimuli after fasting, and hence, the accumulation of LDs would be reduced despite the high concentrations of FFA in the circulating plasma [97]. Cardiac-specific expression of PLIN2 resulted in slower conduction propagation and induced a higher incidence of atrial fibrillation in aged mice [99].
PLIN2 deficiency could result in TAG accumulation in cardiomyocytes, which was seen exclusively in cardiomyocytes but not in cardiac fibroblasts, demonstrating that the effects of PLIN2 deficiency can be cardiomyocytespecific. Reductions in stroke volume and cardiac output were also observed in PLIN2 ${ }^{-1}$ mice. However, there were no significant differences in cardiac function between PLIN2 ${ }^{-/-}$and wild-type mice [98].

\section{Perilipin 5}

PLIN5 is identified predominantly in oxidative tissues, particularly in the heart which is crucial to the cardiac lipid regulation process $[100,101]$. Studies have suggested that PLIN5 functions as a lipolysis inhibitor. PLIN5 protects LDs from lipolysis by forming a shield on the surface of LDs, hence preventing ATGL and HSL from reaching the substrate inside the LDs [102]. The hearts of $\mathrm{PLIN}^{-1-}$ mice are detected with relatively small LDs that lack neutral lipids compared with typical LDs [102]. Consistently, myocardial TAG levels and FA uptake were also markedly reduced, with an increase in glucose uptake and ROS production [103]. The mouse model of cardiomyocyte-specific PLIN5 overexpression (CM-PLIN5) was 
Table 1. Cardiac phenotype in mice with disruption of LDAP genes expression

LDAPs Cardiac phenotype in mice with disruption of LDAP genes expression

\begin{tabular}{|c|c|}
\hline \multicolumn{2}{|c|}{ The PLIN family } \\
\hline PLIN1 & $\begin{array}{l}\text { Global knockout of PLIN1 exhibits enhanced lipolysis which leads to ectopic lipid accumulation with enhanced FA } \\
\text { transportation and oxidation and eventually develop hypertrophic cardiomyopathy along with left-ventricular diastolic } \\
\text { dysfunction at } 20 \text { weeks of age. }\end{array}$ \\
\hline IIN2 & $\begin{array}{l}\text { Transgenic mice with cardiac-specific overexpression of PLIN2 showed accumulation of small LDs around mitochondria and } \\
\text { massive deposition of TAG in the atrium, and they suffered tolerating induced myocardial infarction. } \\
\text { PLIN2 }{ }^{-/-} \text {mice did not show any reduction in myocardial lipid storage but increased TAG accumulation, with normal cardiac } \\
\text { function under baseline conditions or under mild stress. }\end{array}$ \\
\hline PLIN4 & $\begin{array}{l}\text { Mice with PLIN4 deficiency exhibit a marked attenuation in the TAG content along with a concomitant reduction of cardiac } \\
\text { PLIN5 expression but maintained normal cardiac function as WT mice. }\end{array}$ \\
\hline PLIN5 & $\begin{array}{l}\text { PLIN5 }{ }^{-/} \text {mice showed a marked decrease in the content of TAG and FA, along with the generation of ROS significantly } \\
\text { promoted. Aged PLIN5 }{ }^{-/-} \text {mice showed worse cardiac function than their WT littermates. } \\
\text { Cardiomyocyte-specific PLIN5-deficient mice exhibit cardiac steatosis, increased heart weight, left-ventricular hypertrophy, } \\
\text { and mild cardiac dysfunction. }\end{array}$ \\
\hline \multicolumn{2}{|c|}{ Other LDAPs } \\
\hline ABHD5 & $\begin{array}{l}\text { Cardiac-specific ABHD5 knockout mice exhibit cardiomyopathy that is clearly associated with NLSDs and show cardiac } \\
\text { hypertrophy and fibrosis and ventricular dysfunction with massive lipid accumulation in cardiomyocytes. } \\
\text { Cardiac-specific overexpression of ABHD5 blunted cardiomyopathy but did not cause observable detrimental effect under } \\
\text { physiological conditions. }\end{array}$ \\
\hline $\mathrm{SCL} 2$ & Global BSCL2 $2^{-/-}$mice display dramatic loss of fat mass and develop insulin resistance and hypertrophic cardiomyopathy. \\
\hline$\Gamma G L$ & nd exhibit hypertrophic cardiomyo \\
\hline
\end{tabular}

LDAP, lipid droplet-associated proteins; PLIN, perilipin; LD, lipid droplet; TAG, triglyceride; FA, fatty acid; ROS, reactive oxygen species; NLSD, neutral lipid storage disease; BSCL2, Berardinelli-Seip congenital lipodystrophy type 2; ATGL, adipose triglyceride lipase.

found to have a 3.5-fold increase in TAG content in the hearts and exhibited restricted ATGL- and HSL-mediated TAG mobilization [104, 105]. Also, chronic cardiac LD overload may lead to mild cardiac dysfunction with reduced FA oxidation gene expression and compromised mitochondrial function and manifest a phenotype of leftventricular centripetal hypertrophy [104]. In terms of the phenotype, mice with CM-PLIN5 exhibited cardiac steatosis, cardiac weight gain, and mild cardiac malfunction $[100,104,105]$.

PLIN5 deficiency was also closely related to abnormal mitochondrial oxidative capacity. Studies revealed intense targeting of PLIN5 to the interface of cardiac LDs and peridroplet-mitochondria (PDM) but not at the mitochondrial matrix. Treatment with CL316, 243 (CL), the $\beta 3$-adrenergic receptor, elevated this PLIN5 target [106]. PLIN5 contains a mitochondrial recruitment domain $[107,108]$. The LDs of PLIN5-deficient mice tend to dissociate from the mitochondria [103]. In the hearts of
PLIN5-deficient mice, mitochondria exhibited a marked impairment in oxidative capacity by modifying the fattyacyl composition of phospholipids within the mitochondrial membrane, consequently leading to impaired mitochondrial membrane depolarization [108]. In compensation for this, PLIN5 deficiency is able to stimulate mitochondrial proliferation, which was observed in both animal and cellular experiments [109].

Subsequent studies have focused on the role of PLIN5 in different pathophysiological conditions. PLIN5 ${ }^{-/-}$ hearts exhibited postischemic metabolic dysregulation, including a decrease in $\mathrm{C}_{2}$ and $\mathrm{C}_{4}$ acylcarnitine levels, but there was no rise in glycogen levels compared to WT littermates. Moreover, after inducing myocardial infarction by either the $\beta$-adrenergic agonist dobutamine or myocardial stress, the cardiac function of $\mathrm{PLIN}^{-/-}$mice was significantly impaired, accompanied by a reduced survival rate [103]. Zheng et al. [69] later reported that the absence of PLIN5 was character- 
ized by enlarged myocardial infarct size, accelerated impairment of myocardial systolic and diastolic function, reduced cardiac lipid stores, elevated FFAs in the myocardium during myocardial ischemia-reperfusion, severe impairment of the mitochondrial structure and function, elevated levels of ROS and malondialdehyde, and reduced superoxide dismutase activity. A human cohort study on coronary artery disease found that rs884164, a common noncoding polymorphism known to lower the cardiac expression of PLIN5, leads to reduced cardiac function following myocardial ischemia [103]. More recently, Wang et al. [109] treated PLIN5 ${ }^{-/-}$ mice with transverse aortic constriction (TAC) and identified that PLIN5 deficiency aggravated myocardial hypertrophy and caused TAC-induced heart failure. These findings indicate the protective effect of PLIN5 under stress conditions, indicating its role as a treatment solution for cardiomyopathy.

However, one study has observed some contrasting results. In this study, PLIN5 ${ }^{-/}$mice had greater heart weight and showed elevated mRNA expression of heart failure-associated gene myosin heavy-chain beta (Myh7). However, mRNA expression of other heart failure-associated genes such as myosin heavy-chain alpha (Myh6), Nppa, and Nppb did not differ significantly between $\mathrm{PLIN}^{-/-}$and PLIN5 ${ }^{+/+}$mice. Besides, PLIN5 ${ }^{-/-}$hearts exhibited slight alterations in gene expression related to FA and glucose metabolism compared with PLIN5 ${ }^{+/+}$ hearts. Also, myocardial infarct sizes were similar between isolated, perfused PLIN5 $5^{+/+}$and PLIN5 $5^{-/-}$mouse hearts. The researchers also found that PLIN5 ${ }^{-/}$cardiomyocytes retained higher glycogen levels and exhibited enhanced tolerance to hypoxia after preincubation with oleic acid [110]. These findings challenged some of the previous outcomes.

Since most studies have employed global PLIN5 knockout mouse models, cardiomyocyte-specific knockout mice are needed to exclude the effects of systemic lipid dysregulation on the heart in order to investigate the role of PLIN5 on the maintenance of cardiac function. Studies are also needed to further elucidate the function of PLIN5 in the heart and the potential relationship between LDs, PLIN5, and mitochondria.

\section{ABHD5/CGI-58}

Recent studies have characterized another LDAP, ABHD5, also known as CGI-58. ABHD5 localized at cytosolic LDs [111]. PKA phosphorylates both ABHD5 and PLIN5, subsequently dissociating ABHD5 from PLIN5, resulting in the activation of ATGL $[112,113]$. After the activation of ATGL, the initial lipolysis starts, transforming TAG to DAG, contributing to lipotoxicity.

In humans, mutations in genes encoding ABHD5 can lead to a rare and fatal syndrome called the ChanarinDorfman syndrome (CDS), also neutral lipid storage disease (NLSD) $[114,115]$. CDS is characterized by the accumulation of TAG-rich cytoplasmic LDs in most cell types including the cardiomyocytes, and the patients often manifest cardiomyopathy [111]. Although both ABHD5 and ATGL are associated with TAG accumulation in tissues, studies have revealed that their functions are not entirely bound together. On the one hand, patients with impaired ATGL function develop more severe myopathy, whereas mutations in the genes encoding ABHD5 are more associated with the development of ichthyosis, which was unobservable in patients with ATGL deficiency [116]. On the other hand, ABHD5 is found to interact with numerous other lipolysis-regulatory proteins, including PLIN1, PLIN2, PLIN3, and PLIN5 in the PAT family and the FA-binding protein [111]. Patients with NLSD exhibit severe cardiomyopathy, which requires heart transplantation. This clinical phenotype caused by ABHD5 and ATGL mutations indicates that these LDAPs are essential for maintaining normal cardiac function [117].

Jebessa et al. [112] recently explored the specific pathways through which ABHD5 regulated cardiac lipid homeostasis. They found that ABHD5 functions as a serine protease both in vitro and in vivo and cleaves class IIa histone deacetylase 4 (HDAC4) in response to catecholamine stimulation, producing an $\mathrm{N}$-terminal polypeptide labeled HDAC4-NT [112]. However, the activation of ABHD5 for the cleavage of HDAC4 and its association with PKA phosphorylation is still unclear. Studies also found that cardiac-specific ABHD5 knockout mice developed cardiomyopathy related to abnormalities in neutral lipid storage capacity, with massive lipid accumulation in their cardiomyocytes, and predominantly exhibited cardiac hypertrophy and myocardial fibrosis with apparent ventricular dysfunction [112]. Similarly, another muscle ABHD5 knockout mouse model exhibited intracellular deposition of neutral lipids in both cardiac and oxidative skeletal muscles and showed myocardial fibrosis and cardiac remodeling, which may finally result in heart failure. These 2 murine models indicated that cardiac lipid deposition in human CDS patients is probably the result of localized ABHD5 deficiency in the myocardium [118]. Although intracellular lipid deposition was not significantly altered, restoration of HDAT4-NT expression using adeno-associated viruses could attenuate these patho- 
logical myocardial changes by inhibiting the hexosamine biosynthesis pathway [112]. These findings challenge the current knowledge of cardiometabolic diseases by suggesting that lipotoxicity is probably not the only cause of cardiac dysfunction in the development of cardiometabolic diseases. Additionally, a preclinical study showed that cardiac-specific overexpression of ABHD5 slowed the progression of cardiomyopathy with no observable adverse effects under general conditions [119]. Further studies are required to convert this new possible approach to practical application.

\section{Adipose TAG Lipase}

ATGL, also termed patatin-like phospholipase domain containing 2 , is the most researched LDAP. Although ATGLs are primarily detected in the adipose tissue and the breast, they exist in almost all tissues at the protein level [120-123]. ATGL has been reported to localize in the cytoplasm, on the surface of LDs, and in membranes [124-127]. ATGL mainly functions to mediate TAG hydrolysis by converting TAG to a molecule of FFA and another molecule of DAG [128]. ATGL also possesses acylglycerol transacylase activity which allows the transfer of FAs from TAGs to retinols, the hydrolysis of retinyl esters, and acts on TAGs to produce 1,3-DAGs [129]. The truncated mutant ATGL variant lacking the C-terminal protein region of approximately 220 amino acids was unable to localize to LDs and exhibited a marked enhancement in TAG hydrolase activity in vitro, which also suggests that the catalytic activity of ATGL is present in the N-terminal portion $[124,130]$.

Comparative proteomic analysis of both healthy and dysfunctional rat hearts revealed that ATGL expression on the LD surface was significantly reduced in the dysfunctional hearts, whereas overall ATGL expression levels in the heart remained similar, pointing out that ATGL is associated with the maintenance of normal heart function and that ATGL localization rather than expression in the heart contributes significantly to the maintenance of a healthy heart $[32,131]$. Patients with mutations in the gene encoding ATGL would develop NLSD with myopathy, which is characterized by the accumulation of systemic TAG in multiple organs and tissues as well as cardiomyopathy, as described above [124]. Consistently, global ATGL knockout mice showed massive myocardial TAG accumulation along with hypertrophic cardiomyopathy and interstitial fibrosis, which could culminate in heart failure and cardiac death [132]. To exclude the effects of systemic lipid metabolism on the heart, follow-up studies established a cardiac-specific ATGL overexpres-

LDAPs in Cardiomyopathy sion mouse model. They revealed that cardiac-specific ATGL overexpression shielded both diabetic and diet-induced obese mice from developing lipotoxic cardiomyopathy and cardiac steatosis with increased expression of PPARa $[32,133,134]$. Cardiac-specific ATGL overexpression could also protect against stress-induced myocardial contractile dysfunction and contribute to cardiovascular structural remodeling after TAC [135]. Diabetic cardiomyopathy is currently a common secondary cardiomyopathy in clinical practice which has been recently related to lipotoxicity. Both short-term and prolonged hyperglycemic states can induce LD deposition in the myocardium [136-138], which may be attributed to ATGL inhibition in obese type 2 diabetes mellitus individuals [139]. The specific role of LDAPs in the regulation of lipids in diabetic cardiomyopathy needs further characterization.

Further studies investigated the specific underlying mechanisms by which ATGL inhibition causes disturbances in lipid metabolism and ultimately myocardial hypertrophy. Both the pressure overload-induced cardiac hypertrophy mice model induced by abdominal aortic constriction surgery and PE-induced cardiomyocyte hypertrophy in vitro showed decreased ATGL expression and TAG hydrolase activity [128].

ATGL also interacts with many other LDAPs to exert biological effects. PLIN5 and ABHD5 interact with ATGL independently but exhibit opposite effects. ABHD5 is the coactivator of ATGL whose interaction promotes lipolysis. Conversely, the binding between PLIN5 and ATGL results in reduced lipolysis in cardiomyocytes. However, further studies are required to understand whether PLIN5 explicitly inhibits the functioning of ATGL or suppresses all lipases [140, 141]. PLIN2 also mediates the connection between ATGL and LDs. PLIN2 has been shown to decelerate TAG turnover by cutting the interaction between ATGL and LDs [142]. The deletion of BSCL2 is known to increase ATGL protein stability [143]. Also, the hydrophobic domain of G0S2 interacts exclusively with the patatin-like domain of ATGL, thereby inhibiting ATGL from hydrolyzing TAG to DAG and FFA [144].

The researches examined cardiac lipid metabolism in global ATGL knockout mice under pathological conditions to find that downregulation of ATGL did not attenuate postburn cardio-lipid accumulation and cardiac injuries. However, cardiac-specific overexpression of ATGL upregulated glucose transporter 1 expression as well as reduced cardio-lipid accumulation, thus alleviating burn-induced cardiac lipid dysregulation and heart damages [145], suggesting the therapeutic potential of ATGL in the future. 


\section{Conclusion}

Despite the current attempts to describe the interaction between lipids, LDs, LDAPs, and cardiomyopathy, related research is still in its infancy. The current research on LDs and LDAPs mainly concentrates on their function in adipose tissue, the liver, and macrophages. This review focuses on the role of LDs and LDAPs in cardiac lipid regulation and their association with cardiomyopathy. The results from cell culture, preclinical, and clinical studies indicate that the predominant function of the PLIN family is to isolate lipids from lipases, contributing to cardiac lipid accumulation. Some other LDAPs, such as BSCL2, promote the accumulation of cardiac lipids, while others, including ATGL, promote the lipolysis process. The role of ATGL in cardiac lipid regulation is probably the most critical. Several LDAPs interact with ATGL to exert their regulatory function on cardiac lipids. These results on the interaction between LDs, LDAPs, cardiac lipid regulation, and cardiomyopathy in cell and animal experiments need to be further applied to human cardiomyopathy. Do changes in LDAP genes and cardiac lipid regulation disorder really result in cardiomyopathy? Can we combat the development of cardiomyopathy or even reverse its progression by regulating the expression of relevant genes to achieve therapeutic success? Further studies are required to answer these questions.

\section{Acknowledgment}

We thank our laboratory collages for discussion.

\section{Conflict of Interest Statement}

The authors have no conflicts of interest to declare.

\section{Funding Sources}

This work is supported by the Qinfeng Scientific Innovation Project of Fudan University (QF1912) provided to W. Huang.

\section{Author Contributions}

W. Huang wrote the first draft; F. Gao and Y. Zhang participated in discussing the manuscript; C. Tianhui participated in polishing the manuscript; $\mathrm{C}$. Xu revised and finalized the manuscript.

\section{References}

1 Fahy E, Subramaniam S, Murphy RC, Nishijima M, Raetz CR, Shimizu T, et al. Update of the LIPID MAPS comprehensive classification system for lipids. J Lipid Res. 2009;50 Suppl(Suppl):S9-14.

2 Subramaniam S, Fahy E, Gupta S, Sud M, Byrnes RW, Cotter D, et al. Bioinformatics and systems biology of the lipidome. Chem Rev. 2011;111:6452-90.

3 Lopaschuk GD, Ussher JR, Folmes CD, Jaswal JS, Stanley WC. Myocardial fatty acid metabolism in health and disease. Physiol Rev. 2010;90:207-58.

4 Tsushima K, Bugger $\mathrm{H}$, Wende AR, Soto J, Jenson GA, Tor AR, et al. Mitochondrial reactive oxygen species in lipotoxic hearts induce post-translational modifications of AKAP121, DRP1, and OPA1 that promote mitochondrial fission. Circ Res. 2018;122:58-73.

5 Bednarski T, Pyrkowska A, Opasińska A, Dobrzyń P. Regulation of cardiac metabolism and function by lipogenic factors. Postepy Hig Med Dosw. 2016;70:644-53.

6 Ballard FB, Danforth WH, Naegle S, Bing RJ. Myocardial metabolism of fatty acids. J Clin Invest. 1960;39:717-23.

7 Danforth WH, Ballard FB, Kako K, Choudhury JD, Bing RJ. Metabolism of the heart in failure. Circulation. 1960;21:112-23.
8 Sambandam N, Lopaschuk GD, Brownsey RW, Allard MF. Energy metabolism in the hypertrophied heart. Heart Fail Rev. 2002;7: 161-73.

9 Pulinilkunnil T, Rodrigues B. Cardiac lipoprotein lipase: metabolic basis for diabetic heart disease. Cardiovasc Res. 2006;69:32940.

10 Carpenter HM. Myocardial fat infiltration. Am Heart J. 1962;63:491-6.

11 Bharadwaj KG, Hiyama Y, Hu Y, Huggins LA, Ramakrishnan R, Abumrad NA, et al. Chylomicron- and VLDL-derived lipids enter the heart through different pathways: in vivo evidence for receptor- and non-receptor-mediated fatty acid uptake. J Biol Chem. 2010;285: 37976-86.

12 Banke NH, Wende AR, Leone TC, O’Donnell JM, Abel ED, Kelly DP, et al. Preferential oxidation of triacylglyceride-derived fatty acids in heart is augmented by the nuclear receptor PPARalpha. Circ Res. 2010;107:233-41.

13 Lahey R, Wang X, Carley AN, Lewandowski ED. Dietary fat supply to failing hearts determines dynamic lipid signaling for nuclear receptor activation and oxidation of stored triglyceride. Circulation. 2014;130:1790-9.
14 Goldberg IJ, Reue K, Abumrad NA, Bickel PE, Cohen S, Fisher EA, et al. Deciphering the role of lipid droplets in cardiovascular disease: a report from the 2017 National Heart, Lung, and Blood Institute Workshop. Circulation. 2018;138:305-15.

15 Paul A, Chan L, Bickel PE. The PAT family of lipid droplet proteins in heart and vascular cells. Curr Hypertens Rep. 2008;10:461-6.

16 Welte MA, Gould AP. Lipid droplet functions beyond energy storage. Biochim Biophys Acta Mol Cell Biol Lipids. 2017;1862:126072.

17 Saba A, Oridupa O. Lipoproteins and cardiovascular diseases; 2012. p. 197-222.

18 Vrablik TL, Petyuk VA, Larson EM, Smith RD, Watts JL. Lipidomic and proteomic analysis of Caenorhabditis elegans lipid droplets and identification of ACS-4 as a lipid dropletassociated protein. Biochim Biophys Acta. 2015;1851:1337-45.

19 Chitraju C, Trötzmüller M, Hartler J, Wolinski H, Thallinger GG, Lass A, et al. Lipidomic analysis of lipid droplets from murine hepatocytes reveals distinct signatures for nutritional stress. J Lipid Res. 2012;53:2141-52.

20 Schmidt C, Ploier B, Koch B, Daum G. Analysis of yeast lipid droplet proteome and lipidome. Methods Cell Biol. 2013;116:15-37. 
21 Bartz R, Li WH, Venables B, Zehmer JK, Roth MR, Welti R, et al. Lipidomics reveals that adiposomes store ether lipids and mediate phospholipid traffic. J Lipid Res. 2007;48:837-47.

22 Plakkal Ayyappan J, Paul A, Goo YH. Lipid droplet-associated proteins in atherosclerosis (Review). Mol Med Rep. 2016;13:4527-34.

23 Robenek H, Hofnagel O, Buers I, Robenek MJ, Troyer D, Severs NJ. Adipophilin-enriched domains in the ER membrane are sites of lipid droplet biogenesis. J Cell Sci. 2006; 119:4215-24.

24 Pol A, Gross SP, Parton RG. Review: biogenesis of the multifunctional lipid droplet: lipids, proteins, and sites. J Cell Biol. 2014;204: 635-46.

25 Wilfling F, Haas JT, Walther TC, Farese RV Jr. Lipid droplet biogenesis. Curr Opin Cell Biol. 2014;29:39-45.

26 Ost A, Ortegren U, Gustavsson J, Nystrom $\mathrm{FH}$, Strålfors P. Triacylglycerol is synthesized in a specific subclass of caveolae in primary adipocytes. J Biol Chem. 2005;280:5-8.

27 Waltermann M, Hinz A, Robenek H, Troyer $\mathrm{D}$, Reichelt R, Malkus U, et al. Mechanism of lipid-body formation in prokaryotes: how bacteria fatten up. Mol Microbiol. 2005;55: 750-63.

28 Robenek H, Robenek MJ, Buers I, Lorkowski S, Hofnagel O, Troyer D, et al. Lipid droplets gain PAT family proteins by interaction with specialized plasma membrane domains. J Biol Chem. 2005;280:26330-8.

29 Hesse D, Jaschke A, Chung B, Schürmann A. Trans-Golgi proteins participate in the control of lipid droplet and chylomicron formation. Biosci Rep. 2013;33:1-9.

$30 \mathrm{Wu}$ L, Xu D, Zhou L, Xie B, Yu L, Yang H, et al. Rab8a-AS160-MSS4 regulatory circuit controls lipid droplet fusion and growth. Dev Cell. 2014;30:378-93.

31 Zhang S, Wang Y, Cui L, Deng Y, Xu S, Yu J, et al. Morphologically and functionally distinct lipid droplet subpopulations. Sci Rep. 2016;6:29539.

$32 \mathrm{Xu}$ S, Zhang X, Liu P. Lipid droplet proteins and metabolic diseases. Biochim Biophys Acta Mol Basis Dis. 2018;1864:1968-83.

33 Fujimoto Y, Itabe H, Kinoshita T, Homma KJ, Onoduka J, Mori $\mathrm{M}$, et al. Involvement of ACSL in local synthesis of neutral lipids in cytoplasmic lipid droplets in human hepatocyte HuH7. J Lipid Res. 2007;48:1280-92.

34 Gong J, Sun Z, Wu L, Xu W, Schieber N, Xu D, et al. Fsp27 promotes lipid droplet growth by lipid exchange and transfer at lipid droplet contact sites. J Cell Biol. 2011;195:953-63.

35 Le Lay S, Hajduch E, Lindsay MR, Le Lièpvre $\mathrm{X}$, Thiele C, Ferré P, et al. Cholesterol-induced caveolin targeting to lipid droplets in adipocytes: a role for caveolar endocytosis. Traffic. 2006;7:549-61.

36 Zechner R, Zimmermann R, Eichmann TO, Kohlwein SD, Haemmerle G, Lass A, et al. FAT SIGNALS - lipases and lipolysis in lipid metabolism and signaling. Cell Metab. 2012; 15:279-91.
37 Singh R, Kaushik S, Wang Y, Xiang Y, Novak I, Komatsu M, et al. Autophagy regulates lipid metabolism. Nature. 2009;458:1131-5.

38 Kloska A, Wesierska M, Malinowska M, Gabig-Cimińska M, Jakóbkiewicz-Banecka J. Lipophagy and lipolysis status in lipid storage and lipid metabolism diseases. Int J Mol Sci. 2020;21:21.

39 Martinez-Lopez N, Garcia-Macia M, Sahu S, Athonvarangkul D, Liebling E, Merlo P, et al. Autophagy in the CNS and periphery coordinate lipophagy and lipolysis in the brown adipose tissue and liver. Cell Metab. 2016;23: $113-27$.

40 Kiss RS, Nilsson T. Rab proteins implicated in lipid storage and mobilization. J Biomed Res. 2014;28:169-77.

41 Carmona-Gutierrez D, Zimmermann A, Madeo F. A molecular mechanism for lipophagy regulation in the liver. Hepatology. 2015;61:1781-3.

42 Li Z, Schulze RJ, Weller SG, Krueger EW, Schott MB, Zhang X, et al. A novel Rab10EHBP1-EHD2 complex essential for the autophagic engulfment of lipid droplets. Sci Adv. 2016;2:e1601470.

43 Kaushik S, Cuervo AM. Degradation of lipid droplet-associated proteins by chaperonemediated autophagy facilitates lipolysis. Nat Cell Biol. 2015;17:759-70.

44 Kaushik S, Cuervo AM. AMPK-dependent phosphorylation of lipid droplet protein PLIN2 triggers its degradation by CMA. Autophagy. 2016;12:432-8.

45 Barbosa AD, Siniossoglou S. Function of lipid droplet-organelle interactions in lipid homeostasis. Biochim Biophys Acta Mol Cell Res. 2017;1864:1459-68.

46 Traber MG, Kayden HJ. Tocopherol distribution and intracellular localization in human adipose tissue. Am J Clin Nutr. 1987;46:48895.

47 Blaner WS, Li Y, Brun PJ, Yuen JJ, Lee SA, Clugston RD. Vitamin A absorption, storage and mobilization. Subcell Biochem. 2016;81: 95-125.

48 Bozza PT, Bakker-Abreu I, Navarro-Xavier RA, Bandeira-Melo C. Lipid body function in eicosanoid synthesis: an update. Prostaglandins Leukot Essent Fatty Acids. 2011;85:20513.

49 Kraemer FB, Khor VK, Shen WJ, Azhar S. Cholesterol ester droplets and steroidogenesis. Mol Cell Endocrinol. 2013;371:15-9.

50 Shen WJ, Azhar S, Kraemer FB. Lipid droplets and steroidogenic cells. Exp Cell Res. 2016; 340:209-14.

51 Li Z, Thiel K, Thul PJ, Beller M, Kühnlein RP, Welte MA. Lipid droplets control the maternal histone supply of Drosophila embryos. Curr Biol. 2012;22:2104-13.

52 Gallardo-Montejano VI, Saxena G, Kusminski CM, Yang C, McAfee JL, Hahner L, et al. Nuclear Perilipin 5 integrates lipid droplet lipolysis with PGC-1 $\alpha /$ SIRT1-dependent transcriptional regulation of mitochondrial function. Nat Commun. 2016;7:12723.
53 Liu P, Bartz R, Zehmer JK, Ying YS, Zhu M, Serrero G, et al. Rab-regulated interaction of early endosomes with lipid droplets. Biochim Biophys Acta. 2007;1773:784-93.

54 Accioly MT, Pacheco P, Maya-Monteiro CM, Carrossini N, Robbs BK, Oliveira SS, et al. Lipid bodies are reservoirs of cyclooxygenase-2 and sites of prostaglandin-E2 synthesis in colon cancer cells. Cancer Res. 2008;68: 1732-40.

55 Chen X, Xu S, Wei S, Deng Y, Li Y, Yang F, et al. Comparative proteomic study of fatty acidtreated myoblasts reveals role of Cox- 2 in palmitate-induced insulin resistance. Sci Rep. 2016:6:21454.

56 Goldberg IJ, Trent CM, Schulze PC. Lipid metabolism and toxicity in the heart. Cell Metab. 2012;15:805-12.

57 Prevost C, Sharp ME, Kory N, Lin Q, Voth GA, Farese RV Jr, et al. Mechanism and determinants of amphipathic helix-containing protein targeting to lipid droplets. Dev Cell. 2018;44:73-86.e74.

58 Kory N, Farese RV Jr, Walther TC. Targeting fat: mechanisms of protein localization to lipid droplets. Trends Cell Biol. 2016;26:535-46.

59 Liang L, Zhao M, Xu Z, Yokoyama KK, Li T. Molecular cloning and characterization of CIDE-3, a novel member of the cell-deathinducing DNA-fragmentation-factor (DFF45)-like effector family. Biochem J. 2003;370:195-203.

60 Karki S, Farb MG, Sharma VM, Jash S, Zizza EJ, Hess DT, et al. Fat-specific protein 27 regulation of vascular function in human obesity. J Am Heart Assoc. 2019;8:e011431.

61 Li JZ, Lei Y, Wang Y, Zhang Y, Ye J, Xia X, et al. Control of cholesterol biosynthesis, uptake and storage in hepatocytes by Cideb. Biochim Biophys Acta. 2010;1801:577-86.

62 Inohara N, Koseki T, Chen S, Wu X, Núñez G. CIDE, a novel family of cell death activators with homology to the $45 \mathrm{kDa}$ subunit of the DNA fragmentation factor. EMBO J. 1998; 17:2526-33.

63 Goo YH, Son SH, Kreienberg PB, Paul A. Novel lipid droplet-associated serine hydrolase regulates macrophage cholesterol mobilization. Arterioscler Thromb Vasc Biol. 2014; 34:386-96

64 Greenberg AS, Egan JJ, Wek SA, Garty NB, Blanchette-Mackie EJ, Londos C. Perilipin, a major hormonally regulated adipocyte-specific phosphoprotein associated with the periphery of lipid storage droplets. J Biol Chem. 1991;266:11341-6.

65 Henne WM. The molecular era of lipid droplets. Contact. 2020;3:251525642091209.

66 de la Rosa Rodriguez MA, Kersten S. Regulation of lipid droplet homeostasis by hypoxia inducible lipid droplet associated HILPDA. Biochim Biophys Acta Mol Cell Biol Lipids. 2020;1865:158738. 
67 Tansey JT, Huml AM, Vogt R, Davis KE, Jones JM, Fraser KA, et al. Functional studies on native and mutated forms of perilipins. A role in protein kinase A-mediated lipolysis of triacylglycerols. J Biol Chem. 2003;278:84016.

68 Zimmermann R, Strauss JG, Haemmerle G, Schoiswohl G, Birner-Gruenberger R, Riederer $\mathrm{M}$, et al. Fat mobilization in adipose tissue is promoted by adipose triglyceride lipase. Science. 2004;306:1383-6.

69 Zheng P, Xie Z, Yuan Y, Sui W, Wang C, Gao $\mathrm{X}$, et al. PLIN5 alleviates myocardial ischae$\mathrm{mia} /$ reperfusion injury by reducing oxidative stress through inhibiting the lipolysis of lipid droplets. Sci Rep. 2017;7:42574.

70 Xu G, Sztalryd C, Lu X, Tansey JT, Tansey JT, Dorward $\mathrm{H}$, et al. Post-translational regulation of adipose differentiation-related protein by the ubiquitin/proteasome pathway. J Biol Chem. 2005;280:42841-7.

71 Masuda Y, Itabe H, Odaki M, Hama K, Fujimoto Y, Mori M, et al. ADRP/adipophilin is degraded through the proteasome-dependent pathway during regression of lipid-storing cells. J Lipid Res. 2006;47:87-98.

72 Diaz E, Pfeffer SR. TIP47: a cargo selection device for mannose 6-phosphate receptor trafficking. Cell. 1998;93:433-43.

73 Najt CP, Khan SA, Heden TD, Witthuhn BA Perez M, Heier JL, et al. Lipid droplet-derived monounsaturated fatty acids traffic via PLIN5 to allosterically activate SIRT1. Mol Cell. 2020;77:810-e8.

74 Lim HY, Wang W, Wessells RJ, Ocorr K, Bodmer R. Phospholipid homeostasis regulates lipid metabolism and cardiac function through SREBP signaling in Drosophila. Genes Dev. 2011;25:189-200.

75 Schulze PC, Drosatos K, Goldberg IJ. Lipid use and misuse by the heart. Circ Res. 2016; 118:1736-51.

76 Jimenez-Gonzalez S, Marin-Royo G, JuradoLopez R, Bartolome MV, Romero-Miranda A, Luaces M, et al. The crosstalk between cardiac lipotoxicity and mitochondrial oxidative stress in the cardiac alterations in diet-induced obesity in rats. Cells. 2020;9:451.

77 Cedars A, Jenkins CM, Mancuso DJ, Gross RW. Calcium-independent phospholipases in the heart: mediators of cellular signaling, bioenergetics, and ischemia-induced electrophysiologic dysfunction. J Cardiovasc Pharmacol. 2009;53:277-89.

78 Lopaschuk GD, Jaswal JS. Energy metabolic phenotype of the cardiomyocyte during development, differentiation, and postnatal maturation. J Cardiovasc Pharmacol. 2010; 56:130-40.

79 Alpert MA. Obesity cardiomyopathy: pathophysiology and evolution of the clinical syndrome. Am J Med Sci. 2001;321:225-36.

80 Boudina S, Abel ED. Diabetic cardiomyopathy revisited. Circulation. 2007;115:3213-23.

81 Carpenter HM. Myocardial fat infiltration. Am Heart J. 1962;63:491-6.
82 Sletten AC, Peterson LR, Schaffer JE. Manifestations and mechanisms of myocardial lipotoxicity in obesity. J Intern Med. 2018;284: 478-91.

83 Wende AR, Abel ED. Lipotoxicity in the heart. Biochim Biophys Acta. 2010;1801:3119

84 Sharma S, Adrogue JV, Golfman L, Uray I, Lemm J, Youker K, et al. Intramyocardial lipid accumulation in the failing human heart resembles the lipotoxic rat heart. FASEB J. 2004;18:1692-700.

85 D'Souza K, Nzirorera C, Kienesberger PC. Lipid metabolism and signaling in cardiac lipotoxicity. Biochim Biophys Acta. 2016;1861: 1513-24.

86 Liu L, Shi X, Bharadwaj KG, Ikeda S, Yamashita $\mathrm{H}$, Yagyu H, et al. DGAT1 expression increases heart triglyceride content but ameliorates lipotoxicity. J Biol Chem. 2009;284: 36312-23.

87 Chokshi A, Drosatos K, Cheema FH, Ji R, Khawaja T, Yu S, et al. Ventricular assist device implantation corrects myocardial lipotoxicity, reverses insulin resistance, and normalizes cardiac metabolism in patients with advanced heart failure. Circulation. 2012;125: 2844-53.

88 Park TS, Yamashita H, Blaner WS, Goldberg IJ. Lipids in the heart: a source of fuel and a source of toxins. Curr Opin Lipidol. 2007;18: $277-82$.

89 Liu Q, Chen X, Macdonnell SM, Kranias EG, Lorenz JN, Leitges $M$, et al. Protein kinase C $\{$ alpha\}, but not PKC $\{$ beta\} or PKC $\{$ gamma\}, regulates contractility and heart failure susceptibility: implications for ruboxistaurin as a novel therapeutic approach. Circ Res. 2009; 105:194-200.

90 Connelly KA, Kelly DJ, Zhang Y, Prior DL, Advani A, Cox AJ, et al. Inhibition of protein kinase C-beta by ruboxistaurin preserves cardiac function and reduces extracellular matrix production in diabetic cardiomyopathy. Circ Heart Fail. 2009;2:129-37.

91 Wakasaki H, Koya D, Schoen FJ, Jirousek MR, Ways DK, Hoit BD, et al. Targeted overexpression of protein kinase $\mathrm{C}$ beta2 isoform in myocardium causes cardiomyopathy. Proc Natl Acad Sci U S A. 1997;94:9320-5.

92 Stratford S, Hoehn KL, Liu F, Summers SA. Regulation of insulin action by ceramide: dual mechanisms linking ceramide accumulation to the inhibition of Akt/protein kinase B. J Biol Chem. 2004;279:36608-15.

93 Chiu HC, Kovacs A, Ford DA, Hsu FF, Garcia $\mathrm{R}$, Herrero P, et al. A novel mouse model of lipotoxic cardiomyopathy. J Clin Invest. 2001; 107:813-22.

94 Abel ED, O'Shea KM, Ramasamy R. Insulin resistance: metabolic mechanisms and consequences in the heart. Arterioscler Thromb Vasc Biol. 2012;32:2068-76.

95 Fonfara S, Kitz S, Hetzel U, Kipar A. Myocardial leptin transcription in feline hypertrophic cardiomyopathy. Res Vet Sci. 2017;112: 105-8.
96 Brasaemle DL, Dolios G, Shapiro L, Wang R Proteomic analysis of proteins associated with lipid droplets of basal and lipolytically stimulated 3T3-L1 adipocytes. J Biol Chem. 2004;279:46835-42.

97 Ueno M, Suzuki J, Hirose M, Sato S, Imagawa M, Zenimaru Y, et al. Cardiac overexpression of perilipin 2 induces dynamic steatosis: prevention by hormone-sensitive lipase. Am J Physiol Endocrinol Metab. 2017; 313:E699-709.

98 Mardani I, Tomas Dalen K, Drevinge C, Miljanovic A, Ståhlman $M$, Klevstig $M$, et al. Plin2-deficiency reduces lipophagy and results in increased lipid accumulation in the heart. Sci Rep. 2019;9:6909.

99 Sato S, Suzuki J, Hirose M, Yamada M, Zenimaru Y, Nakaya T, et al. Cardiac overexpression of perilipin 2 induces atrial steatosis, connexin 43 remodeling, and atrial fibrillation in aged mice. Am J Physiol Endocrinol Metab. 2019;317:E1193-1204.

100 Mason RR, Watt MJ. Unraveling the roles of PLIN5: linking cell biology to physiology. Trends Endocrinol Metab. 2015;26:144-52.

101 Dalen KT, Dahl T, Holter E, Arntsen B, Londos C, Sztalryd C, et al. LSDP5 is a PAT protein specifically expressed in fatty acid oxidizing tissues. Biochim Biophys Acta. 2007; 1771:210-27.

102 Kuramoto K, Okamura T, Yamaguchi T, Nakamura TY, Wakabayashi S, Morinaga $\mathrm{H}$, et al. Perilipin 5, a lipid droplet-binding protein, protects heart from oxidative burden by sequestering fatty acid from excessive oxidation. J Biol Chem. 2012;287:23852-63.

103 Drevinge C, Dalen KT, Mannila MN, Täng MS, Ståhlman M, Klevstig M, et al. Perilipin 5 is protective in the ischemic heart. Int J Cardiol. 2016;219:446-54.

104 Wang H, Sreenivasan U, Gong DW, O'Connell KA, Dabkowski ER, Hecker PA, et al. Cardiomyocyte-specific perilipin 5 overexpression leads to myocardial steatosis and modest cardiac dysfunction. J Lipid Res. 2013;54:953-65.

105 Pollak NM, Schweiger M, Jaeger D, Kolb D, Kumari M, Schreiber R, et al. Cardiac-specific overexpression of perilipin 5 provokes severe cardiac steatosis via the formation of a lipolytic barrier. J Lipid Res. 2013;54:1092102.

106 Varghese M, Kimler VA, Ghazi FR, Rathore GK, Perkins GA, Ellisman MH, et al. Adipocyte lipolysis affects perilipin 5 and cristae organization at the cardiac lipid droplet-mitochondrial interface. Sci Rep. 2019;9:4734.

107 Wang H, Sztalryd C. Oxidative tissue: perilipin 5 links storage with the furnace. Trends Endocrinol Metab. 2011;22:197203.

108 Andersson L, Drevinge C, Mardani I, Dalen KT, Ståhlman M, Klevstig M, et al. Deficiency in perilipin 5 reduces mitochondrial function and membrane depolarization in mouse hearts. Int J Biochem Cell Biol. 2017;91:913. 
109 Wang C, Yuan Y, Wu J, Zhao Y, Gao X, Chen Y, et al. Plin5 deficiency exacerbates pressure overload-induced cardiac hypertrophy and heart failure by enhancing myocardial fatty acid oxidation and oxidative stress. Free Radic Biol Med. 2019;141:37282.

110 Li Y, Torp MK, Norheim F, Khanal P, Kimmel AR, Stensløkken KO, et al. Isolated Plin5-deficient cardiomyocytes store less lipid droplets than normal, but without increased sensitivity to hypoxia. Biochim Biophys Acta Mol Cell Biol Lipids. 2021; 1866(4):158873

111 Yu L, Li Y, Grisé A, Wang H. CGI-58: versatile regulator of intracellular lipid droplet homeostasis. Adv Exp Med Biol. 2020;1276: 197-222.

112 Jebessa ZH, Shanmukha KD, Dewenter M, Lehmann LH, Xu C, Schreiter F, et al. The lipid droplet-associated protein ABHD5 protects the heart through proteolysis of HDAC4. Nat Metab. 2019;1:1157-67.

113 Pollak NM, Jaeger D, Kolleritsch S, Zimmermann R, Zechner R, Lass A, et al. The interplay of protein kinase A and perilipin 5 regulates cardiac lipolysis. J Biol Chem. 2015; 290:1295-306.

114 Chanarin I, Patel A, Slavin G, Wills EJ, Andrews TM, Stewart G. Neutral-lipid storage disease: a new disorder of lipid metabolism. Br Med J. 1975;1:553-5.

115 Lefevre C, Jobard F, Caux F, Bouadjar B, Karaduman A, Heilig R, et al. Mutations in CGI-58, the gene encoding a new protein of the esterase/lipase/thioesterase subfamily, in Chanarin-Dorfman syndrome. Am J Hum Genet. 2001;69:1002-12.

116 Schweiger M, Lass A, Zimmermann R, Eichmann TO, Zechner R. Neutral lipid storage disease: genetic disorders caused by mutations in adipose triglyceride lipase/PNPLA2 or CGI-58/ABHD5. Am J Physiol Endocrinol Metab. 2009;297:E289-96.

117 Zierler KA, Jaeger D, Pollak NM, Eder S, Rechberger GN, Radner FP, et al. Functional cardiac lipolysis in mice critically depends on comparative gene identification-58. J Biol Chem. 2013;288:9892-904.

118 Xie P, Kadegowda AK, Ma Y, Guo F, Han X, Wang $M$, et al. Muscle-specific deletion of comparative gene identification-58 (CGI58) causes muscle steatosis but improves insulin sensitivity in male mice. Endocrinology. 2015;156:1648-58.

119 Travers JG, McKinsey TA. ABHD5 cleaves HDAC4 to benefit the heart. Nat Metab. 2019;1:1034-5.

120 Knapp M, Gorski J. The skeletal and heart muscle triacylglycerol lipolysis revisited. J Physiol Pharmacol. 2017;68:3-11.

121 Chaves VE, Frasson D, Kawashita NH. Several agents and pathways regulate lipolysis in adipocytes. Biochimie. 2011;93:1631-40.
122 Lass A, Zimmermann R, Oberer M, Zechner R. Lipolysis - a highly regulated multi-enzyme complex mediates the catabolism of cellular fat stores. Prog Lipid Res. 2011;50: 14-27.

123 Schweiger M, Schreiber R, Haemmerle G, Lass A, Fledelius C, Jacobsen P, et al. Adipose triglyceride lipase and hormone-sensitive lipase are the major enzymes in adipose tissue triacylglycerol catabolism. J Biol Chem. 2006;281:40236-41.

124 Cornaciu I, Boeszoermenyi A, Lindermuth H, Nagy HM, Cerk IK, Ebner C, et al. The minimal domain of adipose triglyceride lipase (ATGL) ranges until leucine 254 and can be activated and inhibited by CGI-58 and G0S2, respectively. PLoS One. 2011;6: e26349.

125 Zechner R, Strauss JG, Haemmerle G, Lass A, Zimmermann R. Lipolysis: pathway under construction. Curr Opin Lipidol. 2005; 16:333-40.

126 Soni KG, Mardones GA, Sougrat R, Smirnova E, Jackson CL, Bonifacino JS. Coatomerdependent protein delivery to lipid droplets. J Cell Sci. 2009;122:1834-41.

127 Granneman JG, Moore HP, Granneman RL, Greenberg AS, Obin MS, Zhu Z. Analysis of lipolytic protein trafficking and interactions in adipocytes. J Biol Chem. 2007;282:572635.

128 Gao H, Feng XJ, Li ZM, Li M, Gao S, He YH, et al. Downregulation of adipose triglyceride lipase promotes cardiomyocyte hypertrophy by triggering the accumulation of ceramides. Arch Biochem Biophys. 2015;565:76-88.

129 Gao JG, Simon M. A comparative study of human GS2, its paralogues, and its rat orthologue. Biochem Biophys Res Commun. 2007;360:501-6.

130 Schweiger M, Schoiswohl G, Lass A, Radner FP, Haemmerle G, Malli R, et al. The C-terminal region of human adipose triglyceride lipase affects enzyme activity and lipid droplet binding. J Biol Chem. 2008;283:1721120.

131 Li L, Zhang H, Wang W, Hong Y, Wang J, Zhang S, et al. Comparative proteomics reveals abnormal binding of ATGL and dysferlin on lipid droplets from pressure overload-induced dysfunctional rat hearts. Sci Rep. 2016;6:19782.

132 Haemmerle G, Lass A, Zimmermann R, Gorkiewicz G, Meyer C, Rozman J, et al. Defective lipolysis and altered energy metabolism in mice lacking adipose triglyceride lipase. Science. 2006;312:734-7.

133 Pulinilkunnil T, Kienesberger PC, Nagendran J, Sharma N, Young ME, Dyck JR. Cardiac-specific adipose triglyceride lipase overexpression protects from cardiac steatosis and dilated cardiomyopathy following diet-induced obesity. Int J Obes. 2014;38: 205-15.
134 Pulinilkunnil T, Kienesberger PC, Nagendran J, Waller TJ, Young ME, Kershaw EE, et al. Myocardial adipose triglyceride lipase overexpression protects diabetic mice from the development of lipotoxic cardiomyopathy. Diabetes. 2013;62:1464-77.

135 Kienesberger PC, Pulinilkunnil T, Sung MM, Nagendran J, Haemmerle G, Kershaw EE, et al. Myocardial ATGL overexpression decreases the reliance on fatty acid oxidation and protects against pressure overload-induced cardiac dysfunction. Mol Cell Biol. 2012;32:740-50.

136 Dallak M, Al-Ani B, Abdel Kader DH, Eid RA, Haidara MA. Insulin suppresses type 1 diabetes mellitus-induced ventricular cardiomyocyte damage associated with the inhibition of biomarkers of inflammation and oxidative stress in rats. Pharmacology. 2019; 104:157-65.

137 Sugawara R, Sugiyama H, Nakamura K, Tohgi $\mathrm{K}$, Hongo T, Tsuchiya M, et al. Electron microscopy revealed massive lipid droplets in cardiomyocytes in a patient with cardiogenic shock following a fulminant type $1 \mathrm{di}-$ abetes mellitus. Int Heart J. 2021;62(1):197200.

138 Zhang B, Li X, Liu G, Zhang C, Zhang X, Shen $\mathrm{Q}$, et al. Peroxiredomin-4 ameliorates lipotoxicity-induced oxidative stress and apoptosis in diabetic cardiomyopathy. Biomed Pharmacother. 2021;141:111780.

139 Li X, Wu Y, Zhao J, Wang H, Tan J, Yang M, et al. Distinct cardiac energy metabolism and oxidative stress adaptations between obese and non-obese type 2 diabetes mellitus. Theranostics. 2020;10:2675-95.

140 Granneman JG, Moore HP, Mottillo EP, Zhu Z, Zhou L. Interactions of perilipin-5 (Plin5) with adipose triglyceride lipase. J Biol Chem. 2011;286:5126-35.

141 Wang H, Bell M, Sreenivasan U, Sreenevasan $\mathrm{U}, \mathrm{Hu} \mathrm{H}$, Liu J, et al. Unique regulation of adipose triglyceride lipase (ATGL) by perilipin 5, a lipid droplet-associated protein. J Biol Chem. 2011;286:15707-15.

142 Listenberger LL, Ostermeyer-Fay AG, Goldberg EB, Brown WJ, Brown DA. Adipocyte differentiation-related protein reduces the lipid droplet association of adipose triglyceride lipase and slows triacylglycerol turnover. J Lipid Res. 2007;48:2751-61.

143 Zhou H, Lei X, Yan Y, Lydic T, Li J, Weintraub NL, et al. Targeting ATGL to rescue BSCL2 lipodystrophy and its associated cardiomyopathy. JCI Insight. 2019;5:e129781.

144 Yang X, Lu X, Lombès M, Rha GB, Chi YI, Guerin TM, et al. The $G(0) / G(1)$ switch gene 2 regulates adipose lipolysis through association with adipose triglyceride lipase. Cell Metab. 2010;11:194-205

145 Li L, Zhang X, Zhang Q, Jia J, Zhang J, Zhang $\mathrm{D}$, et al. Myocardial adipose triglyceride lipase overexpression protects against burninduced cardiac lipid accumulation and injury. Oxid Med Cell Longev. 2019;2019: 6428924. 